\title{
Instruments for assessing social phobias in infants and adolescents in the Portuguese language
}

\author{
Instrumentos de avaliação da fobia social para \\ crianças e adolescentes em língua portuguesa
}

\author{
Gabriel José Chittó GAUER \\ Cristine BOAZ \\ Prisla Ücker CALVETTI' \\ Leonardo Machado da SILVA'
}

\begin{abstract}
The diagnosis of social phobia is the most prevalent of the anxiety disorders. Some diagnostic evaluation tools have been validated in Brazil targeting more precise and specific evaluations for each age group. The main objective of this study is to review the tools for assessing social phobias in infants and adolescents, currently validated in Brazil. The most commonly used tools and their purpose to evaluate social phobias are discussed, as well as their interventions. With this goal in mind, a bibliographical review was conducted in databases. The existence was observed of a significant number of studies about tools that have already been evaluated for the assessment of social phobias in infants and adolescents, though with little relevance and narrow application in the clinical setting. Psychotherapeutic interventions for social phobias in Brazil show themselves to be structured and systematic, though there has been no widely employed, validated protocol to help the diagnosis.
\end{abstract}

Uniterms: Adolescents. Evaluation. Children. Social phobia.

\section{Resumo}

O diagnóstico de fobia social é o mais prevalente dentre os transtornos de ansiedade. Alguns instrumentos de avaliação diagnóstica vêm sendo validados no Brasil visando a avaliações cada vez mais precisas e específicas para cada faixa etária. O objetivo deste estudo foi revisar os instrumentos de avaliação da fobia social para crianças e adolescentes validados no Brasil e fazer uma discussão sobre os mais utilizados, bem como sobre as intervenções para este transtorno. Com este objetivo, foi realizada uma revisão bibliográfica em bases de dados. Pôde-se observar um número significativo de estudos sobre instrumentos validados para avaliação de fobia social para crianças e adolescentes, porém com pouca expressão e utilização clínica. Em relação à intervenção da fobia social, o Brasil se destaca nas intervenções psicoterapêuticas estruturadas para auxiliar na melhora do transtorno, embora nenhum protocolo desenvolvido e validado no Brasil tenha sido encontrado neste estudo.

Unitermos: Adolescentes. Avaliação. Crianças. Fobia social.

1 Pontifícia Universidade Católica do Rio Grande do Sul, Programa de Pós-Graduação em Psicologia. Av. Ipiranga, 6681, prédio 11, Sala 931, Jd. Botânico, 90619-900, Porto Alegre, RS, Brasil. Correspondência para/Correspondence to: G.J.C. GAUER. E-mail: <ggauer@pucrs.br>. 
It is considered a normal behaviour for a human being to express social fear at some point in the course of their lives. Social anxiety disorder is manifested in social situations, where anxiety levels rise in the presence of others and it increases with the formality of the situation. It is usually manifested in social interactions combined with the need of social performance, where the individual feels embarrassed, exposed and tries to avoid such situations (American Psychiatric Association - APA, 1994).

The current definition of social phobia is characterized as a marked and persistent fear of one or more social or performance situations where the person is exposed to unfamiliar people or to possible scrutiny by others. The individual fears to react in a way not to show his/her anxiety and attempts to avoid the feeling of embarrassment and humiliation originated from that behaviour (Beidel \&Turner, 1998).

Social phobia is a predominant diagnosis in many epidemiologic studies in the world, as well as in Brazil. Its chronicity and disabling effect is often associated with other disorders (Picon, 2003). The occurrence of social phobia is often associated with major depression and suicides. Suicidal attempts occur frequently in the course of depression, although mostly when combined with social phobia. This disorder also shows high association with alcohol abuse/addiction and somatoform disorder (Briquet's Syndrome) (Vielete, Coutinho \& Figueira, 2004).

Based on populational epidemiologic studies, social phobia is considered the most prevalent within the anxiety disorders. Its multiple causes and ethiologic model is still to be clarified (Beidel \&Turner, 1998; Katzelnick \&Greist, 2001; Kessler etal., 1994). Epidemiological data are also difficult to be obtained based on the diagnostic interviewing techniques currently being utilized. Due to its costly and lengthy methods, many instruments to better diagnose social phobia have become a necessity in order to optimize research and increase the number of studies (Vielete et al., 2004).

Social anxiety may be harmful for the individuals in either short or long term exposure when performing daily activities. Besides, it may prevent the development of abilities and other skills in infants, which could affect their normal adult behaviour, especially in social 94 environments (Gauer, Zogli, Beidel, \& Rodríquez, 2006).
Current literature in Social Phobia considers the Cognitive-Behaviour Therapy (CBT) as the treatment of excellence. Interventions in this form of therapy aim specifically at: reducing the anticipatory anxiety in fearrelated social situations, tackling the physiological symptoms occurred on the course of anxiety, reducing negative self-evaluative cognitions, as well as towards other people, reducing the social-avoidance excuses, treating the associated disorders, reducing patient's social limitations and to improve patient's quality of life. In cases of restricted phobias, the systematic exposure technique has been shown high levels of efficacy. For generalized phobia, the most efficient method of treatment is a combination of both cognitive and behaviour techniques, which have been shown satisfactory overall results and lower probability of recurrence. Each patient needs to be assessed on an individual basis, as CBT techniques may vary depending on the person's technical and functional evaluation (Picon \& Gauer, 2003). These researchers highlight the wide use of the following cognitive techniques: 1) acquaintance with the cognitive model; 2) selfprocessing change, and 3) cognitive re-building. In their opinion, behaviour techniques should be used together with cognitive in order to obtain higher efficacy and longer term results, especially in the generalized subtype of anxiety.

Kapczinski et al. (1999) also suggest the most suitable behaviour techniques to be utilized. Amongst the commonly used are the in vivo systematic exposure, breathing training, progressive muscle relaxation, change the focus of attention and training in social skills in order to ease the individual's insertion in social contexts, promoting a more efficient repertoire to reduce the anxiety facing social interactions.

According to the current scientific literature regarding psychological treatment to social phobia, it was found that there is no current protocol to help assessing this condition and no other instrument in the Portuguese language adapted to the Brazilian reality. The publications in such format are normally created in foreign countries that have a more generic approach to treat social phobia (Beck, 1997) and the same is found in Portugal. However, there are significant studies seeking to make available new clinical instruments to help the investigation of this condition. Gauer, Picon, Vasconcellos, Turner and Beidel (2005) searches the validation for Portuguese of the Social Phobia and Anxiety Inventory 
for Children (SPAI-C), and Vilete, Figueira and Coutinho (2006) attempts the validation to Portuguese of the Social Phobia Inventory (SPIN).

This study aims to review the current literature about validated instruments designed to diagnose social phobia in infants and adolescents which are in the Portuguese language.

\section{Method}

In order to investigate this subject in Brazil and Portugal, a literature review was performed with the help of various database, using the following descriptions:"social phobia and evaluation in children"; "social phobia and evaluation and adolescents"; "social phobia and assessment and children"; "social phobia and assessment and adolescents"; "social phobia and intervention and children"; "social phobia and intervention and adolescents" in the period of year 2000 until March 2008. This search was performed in January 2008 in the following database: Medline, SciELO, Proquest, Psyclnfo, EBSCO, Journal Citation Reports. No studies were found to have been performed in Portugal in either search engine. Besides, several pot-graduate Psychology departments from Portuguese universities were contacted by the authors via email in order to obtain information relevant the subject but there was no reply.

\section{Results and Discussion}

Within the scope of instruments found in the review, the SPAI-C was the only specific instrument for the evaluation of social phobia in infants and adolescents in Brazil currently in use (Gauer et al., 2006). Developed by Beidel and Turner (1998), it embraces the somatic, cognitive and behavioural aspects of infants and adolescents in different social approaches, from eight to fourteen years-old and who are studying up until the third scholar year. It can be used both as clinical settings and as an investigative tool in research.

The SPAI-C is constituted by twenty-six items; some of them include a multiple answer option, using a Likert scale which allows the evaluation of how frequent the symptom is experienced. The maximum score is 52 , indicating a high incidence of anxiety behaviours in a wide variety of social environments. In addiction to its quantitative aspect, the scale could be used qualitatively when examining the pattern of answers in different social contexts. In the studies performed using the SPAI-C, the internal consistency was high (Cronbach Alpha of 0,95), re-test reliability $(r=0,86)$, as well as adequate re-test stability after a 10 month-period $(r=0,63)$. There is practically no reliability difference between boys and girls. The instrument was also submitted to external validation, convergence and discriminative tests, showing its capability to differentiate children with social phobia to those of other psyquiatric diagnosis. There was also a positive correlaction of SPAI-C items with anxiety and other scales measuring the daily situations in which anxiety could arise in infants (Gauer et al., 2005).

The SPAI-C validation process to the Portuguese language was authorized by the Multi-Health Systems Inc. (USA) and included the translation and retrotranslation of the original material in English by Gauer et al., (2000), both were analyzed by a bilingual Child Psychiatrist. Lately, both versions were sent to the original authors for further approval. The instrument was then used in 1952 Brazilian children in scholar age, ranging from 8 to 14 years of age, studying between third and eight year, both from public and private schools in the city of Porto Alegre. Re-test and reliability results were of similar statistical consistence in comparison with the original version in English. Pearson's correlation was 0,883 and Cronbach's Alfa was 0,981 in the totality of the sample (Gauer, Picon, Turner \& Beidel, 2003). After the study with a populational sample, a study is being conducted in order to obtain a discriminative validation. The scores from SPAI-C of a group of infants with social phobia is compared with scores from children with Conduct Disorder and without any other mental health problems. It can also be inferred that for the purpose of validation of this scale, in a clinical sample, it can also be utilized as basis for other similar measures which utilize another method. This is known as convergent validation.

In a study performed by Gauer et al. (2007), an attempt was made to check if SPAI-C was sensitive enough to be utilizad as an instrument to differentiate clinical changes. The researchers included a group of 20 adolescents of both gender ( 14 girls and 6 boys) who had been diagnosed for social phobia with the use of 
the Brazilian version of the "Schedule for Affective Disorders and Schizophrenia, epidemiological version for School Aged-Children (K-SADS-E)". The simple was submitted to a pharmacological intervention for a period of 12 weeks. In time 1 (pre-treatment) the average score was 33,6 (Standard Deviation - SD 7,8); in the second week, the score was 31,2 (SD 9,8); in the fourth week, the average store was 29,1 (SD 12,0); in the eight week the score was 22,6 (SD 12,9); and in the twelveth week the average score was 19,6 (SD 12,5). Using the Bonferroni multiple analysis, it was found a significant reduction of SPAI-C total scores in the weeks 8 and 12 in comparison to pre-treatment (weeks 2 and 4$)(F(4,16)=6,017 ; p=0,004)$. This study highlight that SPAI-C is a sensitive instrument to detect sensible clinical changes in adolescents with social phobia.

Depending on age, SPAI could also be utilized with adolescents, as reported by Olivares, García-Lopez, Hidalgo, Turner and Beidel (1999) in studies to validate the test in Spain in a sample constituted by adolescents. In Brazil, the SPAI, validated by Picon et al. (2005) is designed for the adult population, although it could be performed by adolescents, as long as they have finished the last secondary school year and are at least 17 years-old.

It was also found in the literature the use of K-SADS-E, a semi-structured interview designed to detect and register psychopatologic episods, including those for social phobia, in infants ranging from 6 to 17 years of age, diagnosed under DSM-III and DSM-IIIR criteria. In the K-SADS-E the general classification is obtained during individual interviews, firstly with the parents and then with the respective children, where a short report is obtained based on all available sources of information. Each session in the K-ADS-E begins with a brief description of the condition it is referring to, following by a list of items describing the symptoms of such condition. The interviewer addresses each question with appropriate vocabulary for children and adolescents and the words are again changed when the interview is performed with the parents. There is also a possibility for open questions in order to help to accurately diagnose the individual. Although the questions are formulated in the present and past, the scope permits the evaluation which encompasses the 96 whole life cycle (Mercadante et al., 1995).
In a study performed by Manfro et al. (2003), the focus was the evaluation of traumas and presence of anxiety disorders in the infancy involving twenty-four adult patients with social phobia, and their possible influence for the outcome of the condition. The K-SADS was the instrument of choice, and the researchers reported that $50 \%$ of the patients had a history of trauma prior to their 16 years of age. According to their conclusions, the instrument consisted in a reliable option to help diagnosing anxiety disorders such as social phobia.

It was also found the use of the social phobia inventory (SPIN) - Portuguese version, in a research carried out with adolescents in Brazil. The instrument was originated in England and consists of seventeen items covering topics such as fear, social avoidance behaviours and somatic symptoms, in both performance and social interaction scenarios. The individual is requested to answer how much each item (situations or symptoms) of the questionnaire had had any impact in their lives the week before, with 5 answers ranging from "never" to "always". The scores vary from 0 to 4 each question and from 0 to 68 in overall (Osório et al., 2004; Vilete et al., 2006).

Following the importance of more standardised instruments to help diagnosing Social Phobia, it was found beneficial that protocols could be translated to Brazilian Portuguese, like the one utilized by Olivares (2005) in interventions with adolescents. It was found necessary the validation of other instruments for evaluation, such as the Social Anxiety Scale (SAS-S) for adolescents, validated in Spain and lately utilized by Olivares-Olivares, Rosa-Alcazar and Olivares-Rodriguez (2007).

\section{Conclusion}

In Brazil, there has been no significant validation of instruments for clinical use developed with the purpose of assessing social phobia to the present date. It was found the use of SPAI-C for children's evaluation and both SPAI and SPAI-C for adolescents as main references to diagnose social phobia.

In clinical settings, CBT techniques have demonstrated to be an efficient method of treatment in both Brazilian and international studies. Nevertheless, no validated or developed protocol was found in Brazil 
or Portugal for the assessment of social phobia. It is then concluded that there is still no model for intervention in the treatment of this condition in these countries and that further studies aiming to develop/ validate relevant protocols are in much demand.

\section{References}

American Psychiatric Association. (1994). Task force on nomenclature and statistics. Diagnostic and statistical manual of mental disorders, 4. Washington: APA.

Beck, J. S. (1997). Terapia cognitiva: teoria e prática. Porto Alegre: Artes Médicas.

Beidel, D. C., \& Turner, S. M. (1998). Shy children, phobic adults: nature and treatment of social phobia. Washington: American Psychological Association.

Gauer, G. J. C., Picon, P., Turner, S. M., \& Beidel, D, (2003). Social phobia and anxiety inventory for Children (SPAIC) validation in a Brazilian children sample. In American Psychiatric Association, Annual meeting, Arlington, VA: American Psychiatric Association.

Gauer, G. J. C., Picon, P., Vasconcellos, S. J. L., Turner, S. M., \& Beidel, D. (2005). Social phobia and anxiety inventory for Children (SPAI-C) validation in a Brazilian children sample. Brazilian Journal of Medical and Biological Resesarch, 38, 795-800.

Gauer, G. J. C., Picon, P., Oliveira, M. S., Rodríguez, J. O. Dias, H.Z.J., Isolan, L.R., et al. (2007). Avaliação de mudanças clínicas através do Inventário de Fobia Social para crianças em uma amostra de adolescentes com ansiedade social: dados preliminares. Anais do XXV Congresso Barasileiro de Psiquiatria. São Paulo.

Gauer. G. J. C., Zogbi, H., Beidel, D., \& Rodríguez, J. (2006). Fobia social na infância e adolescência: aspectos clínicos e de avaliação psicométrica. Revista Psico, 37 (3), 263269.

Kapczinski, F., Silveira, R., Picon, P., Fichbein, B., Gauer, G. J. C., Juruena, M. F., et al. (1999). Terapia cognitivo-comportamental e farmacológica da fobia social: uma revisão. Revista de Psiquiatria do Rio Grande do Sul, 21 (1), 52-65.

Katzelnick, D. J., \& Greist, J. H. (2001). Social anxiety disorder: an unrecognized problem in primary care. The Journal of Clinical Psychiatry, 62 (11), 11- 16.

Kessler, R., mcgonagle, K. A., Zhrao, S., Nelson, C. B., Hughes M., Eshleman, S., et al. (1994). Lifetime and 12-month prevalence of DSM-III-R psychiatric disorders in the United States: results from the national comorbidity survey. Archives General Psychiatric, 51 (1), 8-18.
Manfro, G. G., Isolan, L., Blaya, C., Maltz, S., Heldt, E., \& Pollack, M. (2003). Relação entre fobia social na vida adulta e ansiedade na infância. Revista Brasileira de Psiquiatria, 25 (2), 55-60.

Mercadante, M. T., Asbahr, F., Rosário, M. C., Ayres, A. M., Ferrari, M. C., \& Karman, L., (1995). K-SAD: entrevista semi-estruturada para diagnóstico em psiquiatria da Infância:versão epidemiológica. São Paulo: Protc.

Olivares, J. (2005). Protocolo para la intervención en adolescentes con fobia social. Madrid: Ediciones Pirámide.

Olivares, J., García-Lopez, L. J., Hidalgo, M. D., Turner, S. M., \& Beidel, D. C. (1999). The Social phobia and anxiety inventory: reliability and validity in an adolescent Spanish population. Journal of Psychopathology and Behavoral Assessmeent, 21 (1), 67-78.

Olivares-Olivares, P. J., Rosa-Alcazar, A. I., \& OlivaresRodríguez, J. (2007). Validez social de la intervención en adolescentes con fobia social: padres frente a profesores. Terapia Psicológica, 25 (1), 63-71.

Osório, F. L., Crippa, J. A. S., Zuardi, A. W., Graeff, F. G., Busatto, G., Pinho, M., Mazza, M., et al. (2004). Inventário de Fobia Social (SPIN): validação para o Brasil. Anais do XXII Congresso Brasileiro de Psiquiatria (pp. 3-7), Salvador.

Picon P. (2003). Terapia cognitivo comportamental do trastorno de ansiedade social. In R. M. Caminha, R. Wainer \& M. Oliveira (Orgs.), Psicoterapias cognitivo-comportamentais: teoria e prática (pp.129-144). São Paulo: Casa do Psicólogo.

Picon, P., \& Gauer, G. J. C. (2003). Fobia social. In A. C. Neto, G. J. C. Gauer \& N. R. Furtado. (Orgs.), Psiquiatria para estudantes de medicina (pp.422-429). Porto Alegre: EDIPUCRS.

Picon, P., Gauer, G. J. C., Fachel, J. M. G., \& Manfro, G. G. (2005). Desenvolvimento da versão em português do Social Phobia and Anxiety Inventory (SPAI). Revista de Psiquiatria do Rio Grande do Sul, 27 (1), 40-50.

Vilete, L. M. P., Coutinho, E. S. F., \& Figueira, I. L. V. (2004). Reliability of the Portuguese-language version of the Social Phobia Inventory (SPIN) among adolescent students in the city of Rio de Janeiro. Cadernos de Saúde Pública, 20 (1), 89-99.

Vilete, L., Figueira, I., \& Coutinho, E. (2006). Adaptação transcultural para o português do Social Phobia Inventory (SPIN) para utilização entre estudantes adolescentes. Revista de Psiquiatria do Rio Grande do Sul, 28 (1), 40-48.

Received on: 13/8/2008

Approved on: 28/4/2009 